\title{
Indicators for the assessment of biowaste treatment throw through anaerobic digestion
}

\author{
Jelena Pubule, Ivars Veidenbergs, Sarma Valtere, Silvija Nora Kalnins, \\ Dagnija Blumberga
}

Riga Technical University, Institute of Energy Systems and Environment, Kronvalda Blvd. 1, LV-1010 Riga, Latvia

\begin{abstract}
Anaerobic digestion of the organic fraction of municipal solid waste and catering/food waste is one of the best options for biowaste treatment. During the last decades, the waste management system in the Baltic States has changed on a large scale. During the next years, regional waste management will be greatly transformed. The decision to use the thermal treatment of municipal waste to reach the specified legal targets was taken. In Lithuania and Estonia, waste incineration plants have been recently built. Therefore, it is clear that next year's municipal solid waste in Estonia and Lithuania will be incinerated in plants. At the same time, there is a lack of a common vision concerning biowaste treatment in Latvia. Therefore, a well-considered decision must be taken. Anaerobic digestion is one of the best options for biowaste management in Latvia. During the research, indicators for the assessment of biowaste treatment through anaerobic digestion were analyzed. A reduction of GHG emissions is one of the main benefits of this use, or more specifically RES. Therefore, the statistical analysis of data from a decrease in GHG emissions, and the most significant characteristic factors of equipment function, or independent parameters, must be determined. During the research, the empirical model for the identification and analysis of indicators for the assessment of biowaste treatment was carried out. With the created algorithm, a description of the module and the definition of thresholds was achieved. The regression equation, which characterized the connection between the decrease in GHG emissions and the parameters that influence this decrease, will be defined. The results allow for the identification of key indicators in the evaluation of biowaste treatment and its efficiency. The paper presents a multi-factor regression equation to determine the reduction of GHG emissions.
\end{abstract}

Keywords: biowaste treatment; indicators; corelation; regresion; impact assessment methodology.

\begin{tabular}{|ll}
\hline Nomenclature \\
GHG & Greenhouse gases \\
RES & Renewable energy sources \\
AD & Anaerobic digestion \\
DW & Dublin-Watson \\
\hline
\end{tabular}

\section{Introduction}

During the last decades, the waste management system in the Baltic States has changed on a large scale. During the next years, regional waste management will be greatly transformed. The decision concerning the thermal treatment of municipal waste to reach the determined legal targets was made. In Lithuania and Estonia, waste incineration plants have been recently built. Therefore, it is clear that next year's municipal solid waste will be incinerated in plants. At the same time, it is still unclear which options are the optimal scenarios for biowaste treatment in the Baltic States. Nowadays, different methods for municipal solid waste treatment are used, for example: Mechanical Biological Waste Treatment; Stabilization; Incineration with and without energy recovery; anaerobic digestion; composting and controlled landfilling with the collection and utilization of landfill gas.

The situation in Europe is very different in relation to waste treatment technology; for example, the biowaste sector is underdeveloped in the Baltic States, while in Germany the plant operators, due to overcapacities, are ready to import waste

Corresponding author: Jelena Pubule. E-mail address: jelena.pubule@rtu.lv

http://dx.doi.org/10.3846/enviro.2014.045

(C) 2014 The Authors. Published by VGTU Press. This is an open-access article distributed under the terms of the Creative Commons Attribution License, which permits unrestricted use, distribution, and reproduction in any medium, provided the original author and source are credited. 
for treatment from other European Countries. A lot of waste incinerators, facilities for waste and refused derived fuels, have been built and have often been controversially discussed. Since the price of primary energy carriers has increased in the last years, waste as an energy resource becomes more and more attractive.

Anaerobic digestion of the organic fraction of municipal solid waste and catering/food waste is one of the best options for biowaste treatment [2]. Anaerobic digestion has important advantages in comparison with other techniques. In contrast to composting, the anaerobic digestion of biowaste has a simultaneous energetic output [3]. In contrast to landfilling and the utilization of landfill gas, anaerobic digestion provides a closed nutrient cycle. Anaerobic digestion is one of the best options for biowaste management in Latvia. In comparison to waste incineration plants, AD plants need lower investments. The distances for feedstock transport to AD plants are shorter than in the case of waste export to existing waste incineration plants in other countries. Nutrients can be recovered more easily for agricultural production. Furthermore, wet feedstock does not have to be dried, which is required for incineration. Composting is one of the cheapest biowaste treatment options, but in the case of composting, the energy content of the biomass is not utilized.

During the research, the indicators for the assessment of biowaste treatment through anaerobic digestion were analyzed. The reduction of GHG emissions is one of the main benefits from this use, or more specifically RES [4], [5]. Therefore, a statistical analysis of data from the decrease in GHG emissions must be completed, and the most significant characteristic factors of equipment function, or independent parameters, must be determined. The regression equation which characterized the connection between the decrease in GHG emissions and the parameters that influence this decrease must be defined. The results will allow for the identification of key indicators in the evaluation of biowaste treatment and its efficiency.

\section{Methodology}

Empirical data has been processed by using two statistical data processing methods: correlation and regression analysis. The interrelationship, and its proximity between two magnitudes, has been determined through correlation analysis. Regression analysis was used to determine a multiple factor regression model and the statistical significance of its coefficients [6].

The statistical analysis of data, and the multi-factor empirical model, were developed using the computer program STATGRAPHICS.

\section{Results}

\subsection{Data correlation analysis of the reduction of GHG emissions}

The goal of this task is to determine the parameter relationship using a single factor linear model to select the type of regression equation. The correlation of changing magnitudes of dependent and independent variables can be evaluated with the aid of the correlation coefficient. In the case of a single-factor mathematical model, the Pearson expression is used to estimate,

$$
r=\frac{\sum_{i=1}^{m}\left(x_{i}-x\right)\left(y_{i}-y\right)}{(m-1) S_{x} * S_{y}},
$$

where: $x_{i}, y_{i}$ - pairs of independent magnitudes with their respective dependent magnitudes; $x, y$ - arithmetic average values of independent and dependent magnitudes; $S_{x}, S_{y}$ - dispersion of magnitude selections.

With the aid of correlation coefficients, this study evaluates how precise mathematical models describing correlation proximity are. It is accepted that correlation is effective if correlation coefficients are from 0.8 to 0.9 . It must be noted that computer programs for statistical analysis usually calculate the square of the correlation coefficient. If the $\mathrm{R}^{2}$ value is multiplied by 100, then a magnitude (as a percentage) is acquired. This describes the changes in dependent variable magnitudes gained from the empirical equations analysed. For example, $\mathrm{R}^{2}=0,9$ indicates that the equation of the regression to be examined describes $90 \%$ of the changes dependent on random magnitudes.

- Production of biogas $\left(\mathrm{B}_{\mathrm{g}}\right)$ per tonne of biowaste, $\mathrm{m}^{3} / \mathrm{t}$;

- Energy consumption $\left(\mathrm{E}_{\mathrm{ec}}\right)$ per tonne of biowaste, $\mathrm{kWh} / \mathrm{t}$;

- Energy production $\left(\mathrm{E}_{\mathrm{ep}}\right)$ per tonne of biowaste, $\mathrm{kWh} / \mathrm{t}$;

- Heat production $\left(\mathrm{H}_{\mathrm{p}}\right)$ per tonne of biowaste, $\mathrm{kWh} / \mathrm{t}$;

- Fossil fuel substitution $\left(\mathrm{F}_{\mathrm{fs}}\right), \%$.

Only the graphs showing a correlation between the dependent variable magnitude and independent variables are shown below. Changes due to a decrease in greenhouse gases GHG, depending on heat energy produced from biogas, are shown in Figure 1. 


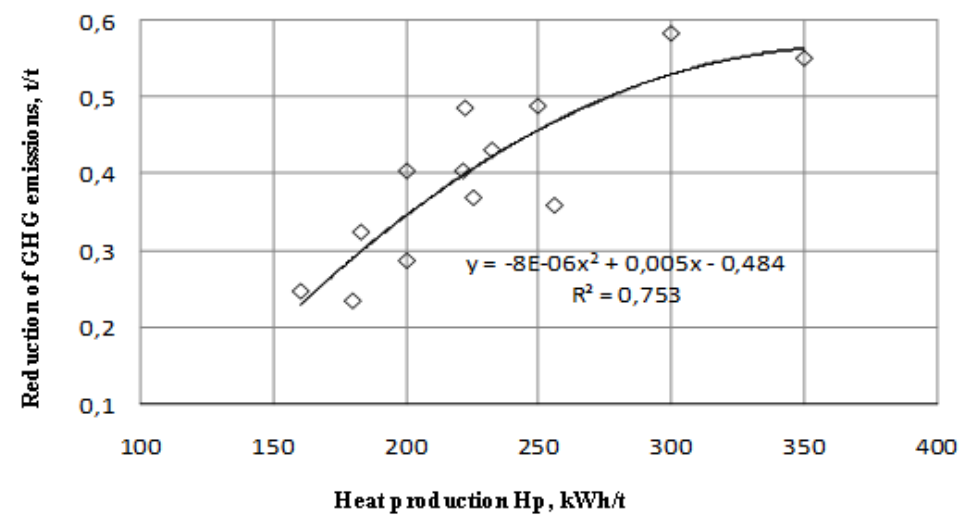

Fig. 1. Decrease in GHG emissions depending on heat production

The figure shows that a mutual correlation between these magnitudes can be observed. The value of the square of the correlation coefficient $\mathrm{R}^{2}=0.75$ and the correlation coefficient $\mathrm{R}=0.87$ were determined through analysis. The relationship between these two magnitudes is non-linear and described by the equation:

$$
G H G=-8 E-06 \cdot H p^{2}+0,005 \cdot H p-0,484 .
$$

Eqn (2) explains $75 \%$ of changes in the examined data, and it can be used for approximate calculations. $25 \%$ of the decrease in GHG emissions is due to the influence of other parameters.

The data correlation analysis shows that a certain correlation between the decrease in GHG emissions and the energy consumption $\mathrm{E}_{\mathrm{ec}}$ exists. The changes in magnitude can be observed in Figure 2.

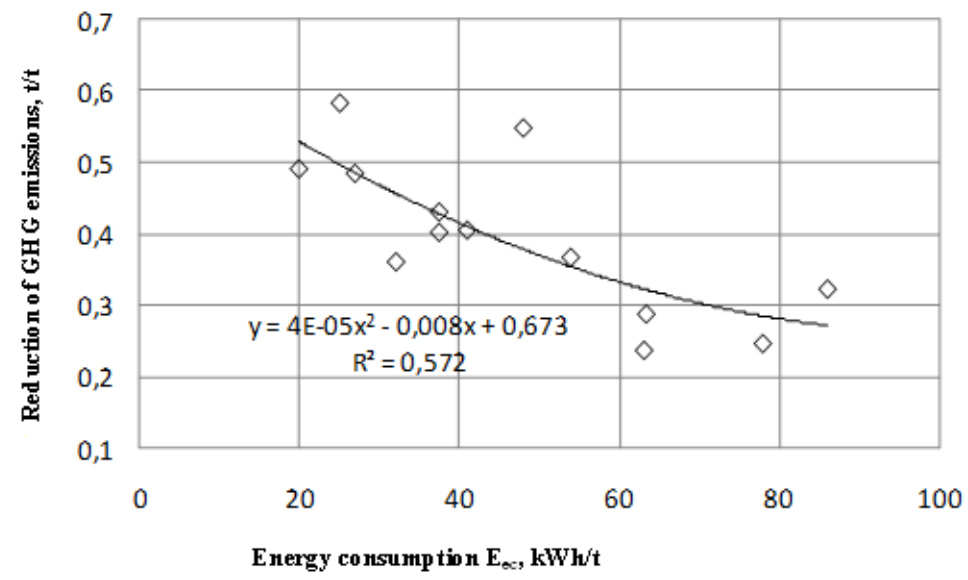

Fig. 2. Reduction of GHG emissions depending on energy consumption

The mutual correlation between the magnitudes examined is characterized by the square of the correlation coefficient $\mathrm{R}^{2}=0.57$, and the correlation coefficient $\mathrm{R}=0.75$. The connection between these magnitudes is non-linear and described by the equation:

$$
G H G=4 E-05 \cdot E e c^{2}-0,008 \cdot E e c+0,673
$$

As the mutual correlation of magnitudes is worse, the Eqn (3) explains only $57 \%$ of the observed changes in data, compared to $75 \%$ in the previous example. Consequently, other parameters show a greater influence $-43 \%$ of the observed decrease in GHG emissions. While observing the correlation of other parameters, it has been determined that a significant correlation is observed between the decrease in GHG emissions and the dependent energy production $\mathrm{E}_{\mathrm{ep}}$. For this reason, a subsequent multi-factor regression analysis examined the changes in the dependent variable magnitude of the decrease in GHG emissions in light of three indicators - energy consumption, energy production, and heat production.

$$
G H G=f(E e c ; E e p ; H p)
$$

The data correlation analysis conducted facilitates a further regression analysis, because it identifies a collection of data to be included in the multi-factor regression equation. 


\subsection{Regression analysis of data from the reduction of GHG emissions}

The goal of regression analysis is to acquire a multi-factor, empirical equation that quantitatively describes the reduction of GHG emissions based on the characteristic and statistically significant indicators from equipment using biogas, and serves as a basis for predictions and evaluations of the reduction of emissions.

The regression analysis determines the precise quantitative parameters of random magnitude changes, that is, determines the significance of the stochastic connection with functional relations.

The regression analysis in this project was conducted in this order:

- the law of distribution of the dependent variable magnitude in the reduction of GHG emissions was verified;

- a regression equation was determined, using the least squares method;

- a statistical analysis of the results obtained was conducted.

The results of the regression analysis are correct if the necessary rules of application are observed [2]. There are many rules, and it is not always possible to follow them all in practice. The main conditions of applying a regression analysis are numerous. The application of the regression analysis is correct in cases where the dependent variable magnitude (reduction of GHG emissions) follows the law of normal distribution. In effect, this requirement is not with respect to independent variable magnitudes. This means that the analysis begins with determining the distribution of dependent variable magnitudes and the analysis can be continued only if the distribution adheres to the law of normal distribution.

The results of the distribution test can be seen in Figure 3. On a logarithmic graph, a normal distribution is graphed as a straight line. In Figure 3, the data to be analysed lies close to the flat curve on the graph. Deviations can be observed at small and large values of capacity. This means that distribution is close to normal, and the application of a regression analysis is valid.

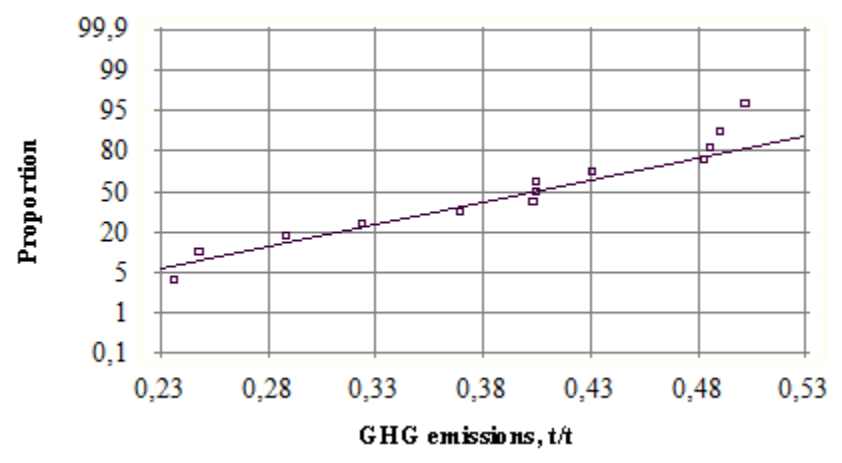

Fig. 3. Distribution of GHG emission values

When creating empirical models in the form of regression equations, several essential questions must always be resolved: does the model include all independent variables that characterise the phenomenon examined, and does the model include superfluous, insignificant variable magnitudes which unnecessarily complicate the model. These questions are answered in the assessment of statistical significance of the magnitudes included in the created model, and the model's distribution analysis [7].

The regression equation determined in the project does not include double and triple interaction effects of independent variables, and it is expressed as:

$$
y=b_{0}+b_{1} x_{1}+b_{2} x_{2}+\ldots+b x=b_{0}+\sum_{i=1}^{n} b_{i} x_{i},
$$

where: $y$-dependent variable magnitude; $b_{0}$ - free agent of the regression; $b_{1} \ldots b_{\mathrm{n}}$ - regression coefficients; $x_{1} \ldots x_{\mathrm{n}}-$ independent variable magnitudes.

The regression equation obtained as a result of the statistical analysis corresponding to expression (1) includes statistically significant independent variables

$$
G H G=b_{0}+b_{1} \cdot E e c+b_{2} \cdot E e p+b_{3} \cdot H p,
$$

where: $E_{e c}$ - energy consumption; $E_{e p}$ - energy production; $H_{p}$ - heat production.

A significance level of $\mathrm{P}=0.1$ was selected for data analysis. This corresponds to a reliability probability of 0.90 . For the assessment of the statistical significance of the coefficients $b_{0} \ldots b_{n}$ of the regression equation (6), criterion $t$ is used, which has a Stjudent distribution with $\mathrm{f}$ degrees of freedom

$$
f=m-(n+1),
$$

where: $m$ - volume of the data collection to be analysed; $n$ - number of independent variables in the regression equation. 
Table 1. The values of regression equation and their assessment

\begin{tabular}{llll}
\hline Coefficients $\mathrm{b}_{\mathrm{i}}$ & Values & $\mathrm{t}$ statistic & P value \\
\hline Constant $\mathrm{b}_{0}$ & 0,2874 & 3,3968 & 0,0079 \\
Coefficient $\mathrm{b}_{1}$ & $-0,00242$ & $-3,6296$ & 0,0056 \\
Coefficient $\mathrm{b}_{2}$ & 0,000257 & 2,644 & 0,0998 \\
Coefficient $\mathrm{b}_{3}$ & 0,000653 & 2,225 & 0,0531 \\
\hline
\end{tabular}

The values of coefficients from the regression equation and their statistical assessment are provided in Table 1 .

The degree of freedom is:

$$
f=m-(n+1)=13-(3+1)=9
$$

The corresponding $t$ criterion for these values from the Stjudent distribution tables is $t_{\text {tab }}=1.9$. As shown in Table 1, the relationship in all cases is $\mathrm{It} I>t_{\text {tab. }}$. This means that all parameters are essential, and must be left in the equation.

As a result of this examination, a regression equation determining the reduction of GHG emissions was obtained, depending on the energy consumption $\mathrm{E}_{\mathrm{ec}}$, the energy production $\mathrm{E}_{\mathrm{ep}}$ and the heat production $\mathrm{H}_{\mathrm{p}}$ from biogas:

$$
G H G=0,2874-0,00241 . E e c+0,000257 . E e p+0,000653 . H p
$$

As a result of the statistical analysis of the data from the created empirical model, the determined $\mathrm{R}^{2}$ value is 0.86 . This means that the created model (8) explains $86 \%$ of the changes in the data to be analysed. The remaining $14 \%$ can be attributed to independent variables not included in the equation, or not defined in the project, or their mutually influential effects.

\subsection{Evaluating the adequacy of the regression equation}

The assessment of the adequacy of the equation (8) is performed with the aid of a dispersion analysis, using the Fisher criterion $\mathrm{F}$. To these ends, the dispersion ratio of the dependent variable magnitude to the remainder dispersion is reviewed:

$$
F\left(f_{1}, f_{2}\right)=\frac{S_{y}^{2}\left(f_{1}\right)}{S_{r e m}^{2}\left(f_{2}\right)},
$$

where: $S_{y}^{2}\left(f_{1}\right)$ - dependent variable magnitude y dispersion; $S_{\text {rem }}^{2}\left(f_{2}\right)$ - remainder dispersion.

The remainder is defined as the difference between the dependent variable magnitude and the value $y_{i}-y_{i}{ }^{\text {cal }}$ which is calculated with the aid of the regression equation.

The value determined with the aid of the dispersion analysis conducted by the computer program is $F=19.16$. The magnitude obtained is compared to the value in the criterion table, which is determined by the value of the degrees of freedom:

$$
f_{1}=m-1=13-1=12 \text { and } f_{2}=m-n=13-3=10
$$

The table value of the Fisher criterion is $\mathrm{F}_{\mathrm{tab}}$. $=2.9$. As can be seen, the relation $\mathrm{F}>\mathrm{F}_{\mathrm{tab}}$, is in effect, and this means that Eqn (8) is adequate and can be used to describe data within the limits of change:

- the reduction of GHG emissions from 0.24 to $0.68 \mathrm{t} / \mathrm{t}$ of biowaste;

- the energy consumption of biogas plant $\mathrm{E}_{\mathrm{ec}}$ from 20 to $86 \mathrm{kWh} / \mathrm{t}$ of biowaste;

- the energy production $\mathrm{E}_{\mathrm{ep}}$ from 146 to $380 \mathrm{kWh} / \mathrm{t}$ of biowaste;

- the heat production $\mathrm{H}_{\mathrm{p}}$ from 160 to $350 \mathrm{kWh} / \mathrm{t}$ of biowaste.

\subsection{Verifying the proper applicability conditions of a regression analysis}

Following the determination of the regression equation, it is possible to verify the proper applicability conditions of the regression analysis with the aid of a string of other indices. These are autocorrelation, multicolinearity and heteroscedasticity.

Autocorrelation test. Using the Durbin-Watson test, a DW criterion has been determined during the course of the statistical processing and analysis of the data. Its value is 1.7 , and that is larger than the limiting value of 1.4. This means that there is no significant remainder autocorrelation observed, and the magnitude assessments made through the analysis using the least squares method have not been distorted.

Multicolinearity test. This test was conducted in the project by analysing the coefficient correlation matrix calculated with the regression equation, and is shown in Table 2 . 
Table 2. Regression equation coefficient correlation matrix

\begin{tabular}{lllll}
\hline Coefficient & Constant & $\mathrm{E}_{\mathrm{ec}}$ & $\mathrm{E}_{\mathrm{ep}}$ & $\mathrm{H}_{\mathrm{p}}$ \\
\hline Constant & 1,0000 & $-0,7828$ & $-0,1487$ & $-0,7830$ \\
$\mathrm{E}_{\mathrm{ec}}$ & $-0,7828$ & 1,000 & 0,0111 & 0,4978 \\
$\mathrm{E}_{\mathrm{ep}}$ & $-0,1487$ & 0,0111 & 1,000 & $-0,4207$ \\
$\mathrm{H}_{\mathrm{p}}$ & $-0,7830$ & 0,4978 & $-0,4207$ & 1,000 \\
\hline
\end{tabular}

The analysis of the regression equation coefficient correlation matrix indicates that there is no significant correlation between coefficients and independent variable magnitudes. This is supported by the low values of the correlation coefficient in Table 2. The values observed in Table 2 are lower than, or close to, 0.5 . This means that the assessment of the regression equation coefficients is correct.

Heteroscedasticity test. This test was conducted in the project by graphically verifying the remaining distribution depending on the energy consumption $\mathrm{E}_{\mathrm{ec}}$ of the biogas plant. If an increase in variation is observed on the graph (points form a triangle or wedge), then heteroscedasticity is present.

The distribution of remainders is shown in Figure 4.

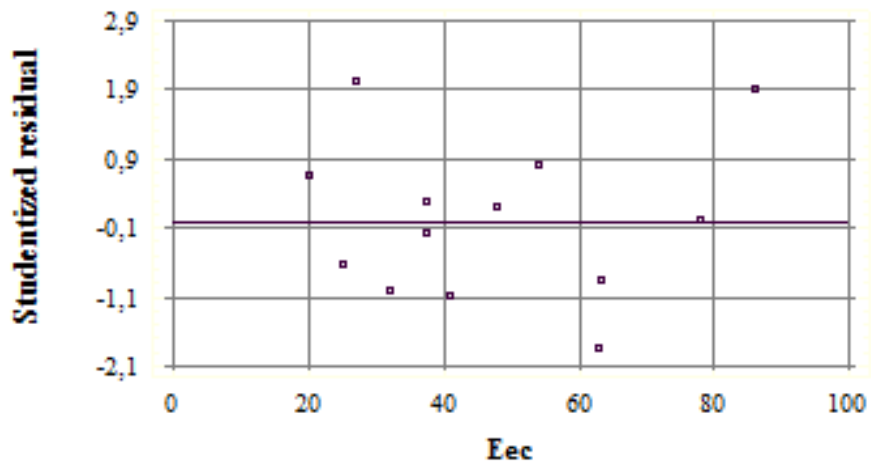

Fig. 4: Remainder distribution depending on the energy consumption of a biogas plant

The figure shows that the collection of data has no significant changes in the remainder distribution when dependent on the energy consumption of the biogas plant Eec. The remainder values are similar throughout the entire range of changes in $\mathrm{E}^{\mathrm{ec}}$. The project includes an examination of the remainder distributions dependent on other factors. The conclusion in all cases is that no heteroscedasticity can be observed, and the standard error has been correctly determined.

One of the ways to verify the regression equation is related to the verification of its member signs, and whether specific changes in the equation have a logical explanation from the aspect of the physical essence of the processes it describes. In the regression equation (8) which determines the reduction of GHG emissions, all parameters, except energy consumption $\mathrm{E}_{\mathrm{ec}}$ have a positive sign, and an increase in their values increases the reduction in GHG emissions. When increasing the energy consumption $\mathrm{E}_{\mathrm{ec}}$ of the biogas plant, the amount of deliverable energy useful to consumers is reduced. As a result, GHG emissions are reduced. The tendencies observed correspond to the actual processes, and can be logically explained.

One of the essential questions in the application of empirical equations is - how completely the results of the regression equation correlate to the data to be analysed. Only in the case of a satisfactory correlation can it be said that the model adequately describes the situation observed in practice, and that its applicability in the modelling of the situation is correct. To verify the adequacy of the empirical equation, empirical and calculated data are compared. Figure 5 shows this data comparison as a graph.

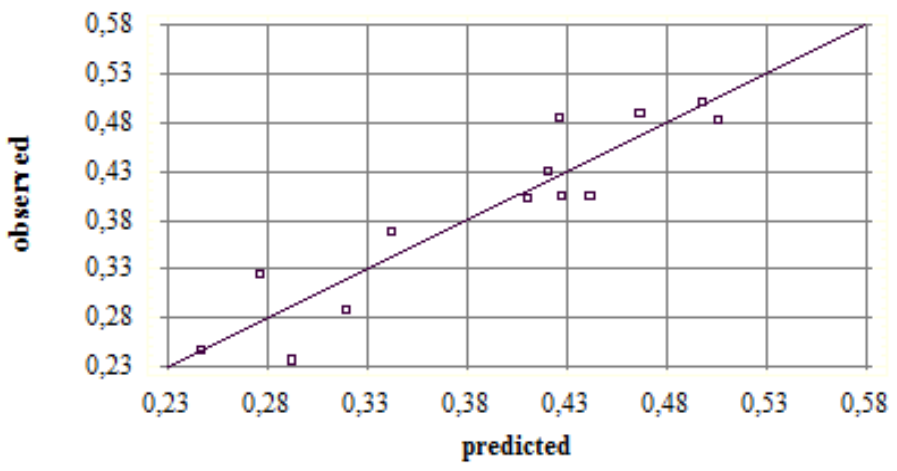

Fig. 5. A comparison of analysable and calculated data showing a reduction of GHG emissions 
As shown in Figure 5, a good correlation between both collections of data can be observed. If the reviewed data precisely correspond to the calculated value, then the points should lie on the flat curve seen in the figure. An increased distribution of points can be seen at low values in the reduction of GHG emissions.

\section{Discussions}

In the statistical analysis of data from the of GHG emissions, using the method of regression analysis, the most significant characteristic factors of equipment function, or independent parameters, have been determined. The connection between the reduction of GHG emissions and the parameters that influence this decrease determine the regression equation obtained during the processing of this data. During the regression analysis each aspect was subjected to verification of the specific step's correctness, and the opportunity to go on to the next step of the analysis.

The completed analysis shows that:

- the reduction of GHG emissions is determined by three statistically significant parameters:

- energy consumption;

- energy production;

- heat production.

- a multi-factor regression equation to determine the reduction of GHG emissions has been obtained, and an adequacy test of the equation using the Fisher criterion has been conducted;

- the equation describes $86 \%$ of changes in the reduction of GHG emissions;

- the application of a data regression analysis is correct, because the dependent variable magnitude - the reduction of GHG emissions is subjected to the normal law of distribution;

- the application of the least squares method in the determination of magnitudes is valid, and the values of these magnitudes are not distorted, because the determined values of the DW criterion are larger than the limits allowed;

- the assessment of the regression equation coefficients is correct, as there is no correlation observed among them;

- the standard error of data analysis has been correctly assessed, because the remainder distribution corresponding to the specific dependent and independent variables is even.

\section{Acknowledgements}

This work has been supported by the European Social Fund project "Involvement of Human Resources for Development of Integrated Renewable Energy Resources Energy Production System" (project No. 2013/0014/1DP/1.1.1.2.0/13/APIA/ VIAA/026).

\section{References}

[1] Moora, H.; Voronova V.; Uselyte R. 2012. Incineration of Municipal Solid Waste in the Baltic States: Influencing Factors and Perspectives, in: Karagiannidis, A. (Ed.), Waste to Energy. Opportunities and Challenges for Developing and Transition Economies, Springer, London, 237-260.

[2] Scano, E. A.; Asquer, C.; Pistis, A.; Ortu, L.; Demontis, V.; Cocco, D. 2014. Biogas from anaerobic digestion of fruit and vegetable wastes: Experimental results on pilot-scale and preliminary performance evaluation of a full-scale power plant, Energy Conversion and Management 77: 2230. http://dx.doi.org/10.1016/j.enconman.2013.09.004

[3] Havukainen, J.; Uusitalo, V.; Niskanen, A.; Kapustina, V.; Horttanainen, M. 2014. Evaluation of methods for estimating energy performance of biogas production, Renewable Energy 66 : 232-240. http://dx.doi.org/10.1016/j.renene.2013.12.011

[4] Schneider, D. R.; Kirac, M.; Hublin, A. 2012. Cost-effectiveness of GHG emission reduction measures and energy recovery from municipal waste in Croatia, Energy 48: 203-211. http://dx.doi.org/10.1016/j.energy.2012.02.008

[5] Rehl, T.; Müller, J. 2013. CO2 abatement costs of greenhouse gas (GHG) mitigation by different biogas conversion pathways, Journal of Environmental Management 114: 13-25. http://dx.doi.org/10.1016/j.jenvman.2012.10.049

[6] Blasnik, M. 1995. The need for statiscital analysis and reporting requirements: some suggestions for regression models, in Proceedings of Energy Program Evaluation Conference, Chicago, USA. p. 14.Lominadze, D. G. 1981. Cyclotron Waves in Plazma. Translated by A. N. Dellis. 1st ed. Oxford: Pergamon Press. 206 p. ISBN 0-08-021680-3.

[7] Stock, J. H.; Watson, M. W. Introduction to Econometrics. Addison Wesley, 696. 